\title{
High-frequency earthquake swarm associated with the May 1991 dome extrusion at Unzen Volcano, Japan
}

\author{
Kodo Umakoshia,", Naoko Itasaka ${ }^{\mathrm{b}}$, Hiroshi Shimizuc
}

a Faculty of Environmental Studies, Nagasaki University, 1-14 Bunkyo-machi, Nagasaki 852-8521, Japan

${ }^{\mathrm{b}}$ Graduate School of Science and Technology, Nagasaki University 1-14 Bunkyo-machi,

Nagasaki 852-8521, Japan

'Institute of Seismology and Volcanology, Faculty of Sciences, Kyushu University,

2-5643-29 Shin-yama, Shimabara, Nagasaki 855-0843, Japan

* Corresponding author. Tel./fax: +8195819 2766.

E-mail address: umakoshi@nagasaki-u.ac.jp (K. Umakoshi).

Submitted to Journal of Volcanology and Geothermal Research 


\section{Abstract}

The 1990-1995 eruption of Unzen Volcano in southwestern Japan was characterized by the extrusion of a dacite lava dome and frequent pyroclastic flows during the dome growth. Associated with the dome emergence on May 20, 1991, an intense swarm of high-frequency (HF) microearthquakes occurred just beneath the crater at very shallow depths. We used data from FG3, a seismic station located $500 \mathrm{~m}$ SSW of the crater, to identify 29,401 HF earthquakes between May 11 and 31, 1991. The rate of HF earthquakes increased starting on May 12 and peaked on May 17. The high seismicity continued until May 26, then dropped sharply, coinciding with a marked decline in the swelling on the southern upper flank of the volcano. The seismicity increased and decreased repeatedly within a $1^{-}$to 2 -h period, which was correlated with tilt cycles observed $680 \mathrm{~m}$ west of the crater in such a way that the seismicity increased during uplifting on the craterward side. Defining an earthquake group as a series of earthquakes with waveforms that are similar or vary only slightly over time, we identified 10 such groups, each containing more than 300 events. The largest group comprised 3,214 events over 18 days. Seismicity rates of eight groups, including the largest, increased and decreased repeatedly, correlated with the tilt cycles. As the waveform data from station FG3 were considerably clipped for relatively large events, we analyzed data from two additional stations, KRA and CJA, located 3.5 and $8.7 \mathrm{~km}$ from the crater, respectively, and identified a total of five new groups. The activity of two groups recorded at KRA was correlated with the tilt cycles, but those of three groups recorded at CJA did not always show such a correlation. Hypocenters for the groups recorded at KRA were distributed to the east side of the conduit and a focal mechanism suggested that the events in this area occurred due to compressional stress produced by the inflation of the conduit. The groups recorded at CJA occurred to the 
north side of the dike trending westward from the conduit. The focal mechanisms have P-axes roughly trending to the dike, which can be explained by the compressional stress generated by the increasing thickness of the dike.

Keywords: seismicity; high-frequency earthquake; cyclic activity; cross-correlation; lava dome; Unzen 


\section{Introduction}

Unzen Volcano is located in the central part of the Shimabara Peninsula in southwestern Japan. The most recent eruption took place from 1990 to 1995 at Mt. Fugen (Fugendake), the main peak of Unzen Volcano. The volume of extruded lava during this eruption is estimated to be about $2 \times 10^{8} \mathrm{~m}^{3}$ (Nagaoka et al., 1996), much larger than that extruded during the two previous eruptions $\left(5 \times 10^{6} \mathrm{~m}^{3}\right.$ in 1663 and $2 \mathrm{x}$ $10^{7} \mathrm{~m}^{3}$ in 1792) (Ohta, 1993). The 1990-1995 eruption extruded dacite lava from Jigokuato Crater, one of the summit craters and formed a lava dome, whereas the two previous eruptions ejected lava from the northern upper flank of Mt. Fugen and generated lava flows. Eruptions that form lava domes within the Myoken Caldera, where Mt. Fugen is located, occur every 4000 to 5000 years, including the 1990-1995 eruption (Nakada et al., 1999).

The lava dome associated with the 1990-1995 eruption emerged on May 20, 1991, about 6 months after the first phreatic eruption on November 17, 1990. As various observations had been made since the first eruption (e.g., Geophysical Party, Joint University Research Group, 1992), some marked changes in the data were detected for about two weeks around the beginning of the dome extrusion. On May 12, high-frequency (HF) microearthquakes began to occur at very shallow depths just beneath the crater, and the seismicity continued to intensify. On May 13, inflation of the southern upper flank of Mt. Fugen was detected by electron-optical distance measurements (EDM) (Saito et al., 1993). In addition, remarkable changes were observed in the total geomagnetic field near the crater (Tanaka et al., 1994) and in ground tilt $680 \mathrm{~m}$ west of the crater (Yamashina and Shimizu, 1999). Furthermore, many WNW-ESE cracks were developed on the surface near the crater. Using photogrammetric analysis, Yasuda et al. (1993) revealed that a WNW-ESE trending 
graben about $250 \mathrm{~m}$ width and $300 \mathrm{~m}$ long had formed in this area.

Several studies of one of these phenomena, the HF earthquake swarm, have been conducted. Sudo et al. (1992) installed a seismic station $2 \mathrm{~km}$ SSW from the crater and detected a group of earthquakes with similar waveforms. This activity continued from May 14 until the end of May, with the waveforms progressively varying slowly over time. A similar study was carried out by Umakoshi et al. (2008), who used cross-correlation analysis to examine waveforms recorded at station FG3 (Fig. 1) and detected many earthquake groups within the swarm. Shimizu et al. (1997) determined hypocenters for relatively large events via the master event method using data from six seismic stations FG1, FG2, FG3, TKE, FKE, and KRA (Fig. 1). They demonstrated that in May 1991, the hypocenters were concentrated in two areas beneath the crater at depths ranging from 600 to $1000 \mathrm{~m}$ above sea level (Fig. 2).

Despite this research, the HF earthquake swarm in May 1991 has not yet been fully studied. For example, the temporal variation of the seismicity rate has not been investigated in detail, making it difficult to compare the swarm activity with other data. In addition, the characteristics of the earthquake groups detected by Umakoshi et al. (2008) have yet to be investigated. In this paper, we reveal the characteristics of this swarm, analyze earthquake groups, and discuss the relationship between the swarm activity and ground deformation data (Yamashina and Shimizu, 1999) to infer the process generating the swarm associated with the lava dome extrusion at Unzen Volcano in May 1991.

\section{Data}

Fig. 1 shows the locations of seismograph stations in the central part of the Shimabara Peninsula that were installed by the Shimabara Earthquake and Volcano 
Observatory (SEVO) (now known as the Institute of Seismology and Volcanology) of Kyushu University. Signals were telemetered to SEVO and were recorded continuously on digital audiotapes with a sampling rate of $100 \mathrm{~Hz}$ (Shimizu et al., 1992). We used waveform data from FG3, a seismic station located $500 \mathrm{~m}$ SSW of the crater. We also used data from stations KRA and CJA, located 3.5 and $8.7 \mathrm{~km}$ from the crater, respectively, to analyze relatively large events, for which waveforms recorded at FG3 were considerably clipped. Each station had a 1-Hz vertical-component seismometer.

In this study, we analyzed seismic data for the period between May 11 and 31, 1991. Although Umakoshi et al. (2008) have created a data set of P-wave arrival times at FG3, we improved the data by checking continuous seismograms visually and obtained a revised data set consisting of 32,914 events with maximum amplitudes $\geq 1.0$ x $10^{-5} \mathrm{~m} / \mathrm{s}$. Of these, we classified 29,401 events as HF earthquakes, defined as those with waveforms that have abundant spectral components higher than $5 \mathrm{~Hz}$. The remaining 3,513 events were classified as low-frequency (LF) earthquakes. This classification was generated automatically by spectral analysis using fast Fourier transforms (FFT) with a window length of $2.56 \mathrm{~s}$ starting $0.25 \mathrm{~s}$ before the onset.

P-wave arrival time data for KRA and CJA were created by selecting events with maximum amplitudes $\geq 3 \times 10^{-6} \mathrm{~m} / \mathrm{s}$ for each station on the basis of the $\mathrm{P}$-wave arrival time data at FG3. There are 2,044 and 182 selected events for KRA and CJA, respectively. No waveform data were recorded at KRA from 11:52 to 17:50 on May 16. We determined magnitudes for the 182 events selected at CJA using the formula given by Watanabe (1971). In the calculation, we used maximum amplitudes of the vertical component recorded at seismic stations in and around the Shimabara Peninsula. Magnitudes determined by this method have been shown to be roughly consistent with those determined by the Japan Meteorological Agency (JMA) (Umakoshi et al., 2001). 


\section{Seismicity}

Table 1 shows the daily number of HF and LF earthquakes and pyroclastic flows. Pyroclastic flow data were obtained from the Fukuoka District Meteorological Observatory (1996). During the study period, HF seismicity rates were much higher than LF seismicity rates. Fig. 3(a) shows the number of HF earthquakes in 6-h intervals from May 11 to 31, 1991. The black and gray bars indicate the number of events with maximum amplitudes $\geq 3 \times 10^{-5} \mathrm{~m} / \mathrm{s}$ and between $1 \times 10^{-5}$ and $3 \times 10^{-5} \mathrm{~m} / \mathrm{s}$, respectively. Small closed circles above the bars indicate periods when the seismograms were disturbed by debris flows due to heavy rainfall and the observed seismicity rates were consequently reduced. After May 24, pyroclastic flow signals prevented identification of earthquakes for 1 to $3 \mathrm{~h}$ per day. Earthquake counts increased beginning during the 00:00 to 06:00 interval on May 12 and peaked in the 18:00 to 24:00 interval on May 17, about 2 days before the dome emergence. The high seismicity was steady until the counts dropped suddenly after the 12:00 to 18:00 interval on May 26. Although debris flows occurred on May 26 and pyroclastic flows increased markedly on and after May 26 (Table 1), those events cannot explain the sudden decrease in seismicity. The period of high seismicity is correlated with that of the swelling of the southern upper flank of Mt. Fugen observed by EDM (Saito et al., 1993). Fig. 3(b) shows the magnitudes for 182 events selected at CJA over time. The maximum magnitude was 2.0, which occurred at 09:46 on May 16. After May 18, the upper limit of magnitudes was nearly constant at about 1.5 through time although the incidence rate changed, reaching the highest level in the period between May 19 and 20 .

Fig. 4 shows the tilt variations and the earthquake counts at 10-min intervals on May 16 and 17. The tilt data were obtained $680 \mathrm{~m}$ west of the crater and were recorded at 10-min intervals with a resolution of 0.5 urad (Yamashina and Shimizu, 1999). As 
indicated by vertical dotted lines, tilt cycles with periods of 1 to $2 \mathrm{~h}$ in the $\mathrm{E}-\mathrm{W}$ component were correlated well with repeated increases and decreases in the seismicity, that is, periods of high seismicity rates coincided with periods of eastward (i.e., craterward) uplift. In contrast, when the eastward ground was subsiding, seismicity rates were much lower. In most cases, the earthquake count peaks coincided with the times when the eastward uplift started or accelerated. The periodic increase and decrease of seismicity was observed throughout the study period. The correlation of the HF seismicity with the tilt cycle can be recognized from May 12 through 20, the period for which Yamashina and Shimizu (1999) presented tilt data.

\section{Earthquake groups}

\subsection{Method}

We investigate characteristics of earthquake groups mentioned in Section 1. The term "earthquake group" refers to a series of earthquakes with waveforms that are similar or vary only slightly over time (Umakoshi et al., 2002). According to this definition, waveforms in an earthquake group may be similar for all pairs or may change significantly from the start to the end of its activity. Therefore, this categorization can be regarded as an expansion of the well-known concept of the "earthquake family" (Hamaguchi and Hasegawa, 1975; Okada et al., 1981). To identify earthquake groups, we adopted the method developed by Umakoshi et al. (2002).

For preparation, we used all events individually as reference events, calculating peak cross-correlation coefficients (PCCs) between each reference event and events that occurred within $24 \mathrm{~h}$ before and after the reference event. A PCC is defined as the maximum value of the cross-correlation coefficients obtained by fixing the reference waveform and shifting the other waveform within a range of $\pm 1 \mathrm{~s}$. The correlation 
window length was $3.0 \mathrm{~s}$, starting $0.1 \mathrm{~s}$ before the onset. Fig. 5 shows the number of events with $\mathrm{PCC} \geq 0.6$ within $24 \mathrm{~h}$ of each reference event. The horizontal axis is the occurrence time of the reference event. The threshold PCC was selected based on the examination by Umakoshi et al. (2008). In Fig. 5, there are many clusters of dots with peaked distributions, each of which suggests the occurrence of an earthquake group.

We extracted the events comprising each peaked distribution in Fig. 5. The parameters noted below were chosen as the most appropriate values after testing several alternatives. Fig. 6(a) shows an enlargement of Fig. 5 during the period between May 13 and 19. We chose the event at the peak of the distribution (the double circle in Fig. 6(a)) as an initial reference event. PCCs were calculated between this reference event and events occurring 1 to $2 \mathrm{~h}$ later to search for the event with the maximum PCC. If the maximum PCC was equal to or greater than 0.7 , that event was selected as a new reference event, and the same process was repeated. In the case that no events with $\mathrm{PCC} \geq 0.7$ were found, the search period was extended to $48 \mathrm{~h}$ after the last reference event. The same process was also conducted backward from the initial reference event. The closed circles in Fig. 6(a) indicate the reference events selected using this procedure.

Next, using the selected reference events (double circles and closed circles in Fig. 6(a)), PCCs were calculated between each reference event and all events occurring within $24 \mathrm{~h}$ before and after the reference event, and events with $\mathrm{PCC} \geq 0.6$ were extracted. All extracted events, including the reference events, were determined to represent an earthquake group. Fig. 6(b) shows the remaining events after removing those belonging to the group. Data in Fig. 6(b) can be used to select a new reference event for identifying another earthquake group. 
We identified 10 earthquake groups from the FG3 data, each containing more than 300 events. We named these groups F1 through F10 (Table 2). Fig. 7 shows the waveforms of the initial reference events and their normalized amplitude spectra. The spectra were calculated using FFT with a window length of $5.12 \mathrm{~s}$ starting $0.5 \mathrm{~s}$ before the onset. These reference events generally have broad spectral bandwidths. Fig. 8 shows the hourly number of events for each group. The activities of these groups began consecutively between May 12 and 19. Among these groups, F4 is the largest in terms of number of events as well as in duration, comprising 3,214 events over 18 days. Also, it includes many relatively large events compared to the other groups. F4 is considered to be the same group identified by Sudo et al. (1992) and described in Section 1.

The active periods of many groups overlapped; therefore, we compare the activities among the groups in detail. Fig. 9 shows the earthquake counts for each group in 5-min intervals from (a) 07:00 to 18:59 on May 16 and (b) 12:00 to 23:59 on May 17. The vertical dotted lines are drawn on the count peaks for group F3 or F6. The bottom figure shows the earthquake counts for all HF events. Among these groups, F3 through F7 are correlated with the tilt cycles, being activated mainly during the periods of craterward uplift. We can classify these five groups into two types: the first type comprises F3, F6, and F7, which are characterized by short activity duration $(<10 \mathrm{~min})$ in each cycle, whereas the second type comprises groups F4 and F5, which have long durations $(>30$ min). When both first- and second-type groups appeared during the same cycle, the initiation of the second-type groups generally lagged behind that of the first-type groups by about 5 min. The activity of group F8 was nearly constant over time, and was not connected with the tilt cycles. Of the remaining groups, F1, F2, and F10 were classified as the second type, and F9 showed the same pattern as F8. 


\section{$4.3 \mathrm{KRA}$ and CJA}

Data from KRA and CJA were used for identifying groups with relatively large events. The criterion for membership in a group based on data from KRA and CJA necessarily differs from that for data from FG3; however, we did not take this into consideration. Fig. 10 shows the number of events with $\mathrm{PCC} \geq 0.6$ within 24 h (KRA) or $72 \mathrm{~h}$ (CJA) before and after each reference event. The correlation window length is $8.0 \mathrm{~s}$ starting $0.1 \mathrm{~s}$ before the onset. Adopting the same threshold PCC values that we used for FG3, we identified two groups for KRA (K1 and K2) and three for CJA (C1, C2, and C3) (Table 2). The initial reference events are shown by open circles in Fig. 10. Closed circles, triangles and squares in Fig. 10 (bottom) indicate the events belonging to groups C1, C2, and C3, respectively, as a result of identifying groups. Fig. 11 shows the waveforms of the initial reference events and their normalized amplitude spectra. Spectral amplitudes lower than $5 \mathrm{~Hz}$ are dominant for these waveforms. This is probably because high-frequency energy was attenuated due to the long propagation path, as high-frequency components were observed in the waveforms of same events recorded at FG3. We identified 445 events in common between F4 and K1, suggesting that these two groups are largely the same group. Events belonging only to K1 were relatively large, and their waveforms recorded at FG3 were considerably clipped. Among the CJA groups, C1 included the largest events during the study period ( $M 2.0$ on May 16) and contained 18 of the 19 events having $M \geq 1.5$.

Fig. 12 shows the tilt variations and earthquake counts in 10-min intervals on May 20 for $\mathrm{K} 1$ and $\mathrm{C} 1$. The vertical dotted lines are drawn to show the relation between the tilt cycles and the earthquake occurrences. In most cases, earthquakes in K1 occurred during eastward uplifting. In contrast, the correlation between $\mathrm{C} 1$ and the tilt cycles was not always clear; that is, earthquakes occurred even during periods of 
eastward subsidence as indicated by closed circles above the vertical dotted lines. K2 had characteristics similar to K1, while C2 and C3 resembled C1.

\section{Discussion}

As shown in Fig. 4, the HF seismicity increased and decreased with a period of about 1 to $2 \mathrm{~h}$, which correlated well with the tilt cycles. Yamashina (1995) confirmed that the cyclic tilt variations trending to the crater were simultaneously recorded at several stations in the summit area and estimated its source depth to be less than a few hundred meters below the crater. It is assumed that the cyclic tilt is caused by repeated inflation and deflation of the conduit.

Periodic behavior in lava dome eruptions has been observed on various time scales (e.g., Barmin et al., 2002; Garcia-Aristizabal et al., 2007). At Soufrière Hills Volcano, Montserrat, hundreds of cycles with periods of $3-30 \mathrm{~h}$ were observed in 1996-1997 (Voight et al., 1998; Voight et al., 1999; Miller et al., 1998). Voight et al. (1999) indicated that swarms began when inflations were underway and they stopped near the peak of inflation or the start of deflation. More detailed examination by Neuberg et al. (2006) revealed that a swarm commenced when the time derivative of tilt reached a maximum and ceased when it reached a minimum. Although a detailed comparison is difficult because the tilt cycle amplitude recorded at Unzen was much smaller and the cycle period was much shorter, the correlation of seismicity with tilt cycles shown in Fig. 4 is similar to that observed at Soufrière Hills.

To explain the correlation of seismicity with tilt cycles at Soufrière Hills, Denlinger and Hoblitt (1999) proposed a model of Newtonian flow of compressible magma through a conduit combined with a stick-slip condition along the conduit wall. Neuberg et al. (2006) proposed a seismic trigger model based on brittle failure of magma 
due to high strain-rates. However, these models do not apply to Unzen because of differences between these two volcanoes. First, the dominant event type differs, that is, LF earthquakes with a spectral contents of $0.2-10 \mathrm{~Hz}$ occurred at Soufrière Hills (Green and Neuberg, 2006; Neuberg et al., 2006), whereas HF earthquakes with broader spectral bandwidths occurred at Unzen (Fig. 7). HF earthquakes at Unzen are considered to be volcano-tectonic events, which represent brittle failure resulting from strain induced by volcanic processes (Power et al., 1994). It seems reasonable to assume that the HF earthquakes occurred in the stiff rock near the conduit. Second, the cyclic tilt continued throughout the entire period of lava extrusion over three years at Unzen, and its amplitudes grew when the magma supply rate increased (Yamashina, 1995). In June 1991, however, the seismicity dropped sharply despite the high magma supply rate (Umakoshi et al., 2008). This drop indicates that the cyclic tilt at Unzen did not always correlate with seismicity throughout the lava extrusion. The low seismicity rate in June 1991 may suggest that the rocks in the focal area had been fractured strongly by the numerous HF events beginning from May 12 .

Green and Neuberg (2006) classified the LF earthquakes that were recorded at Soufrière Hills into families and revealed that the families were persistent across swarms and that the order of initiation across swarms remained constant for many families. These characteristics of families suggest that sources at the same locations were being activated repeatedly in the same manner. As mentioned in Section 4.2, a similar trend is found in our results. The first- and second-type groups identified in Fig. 9 were likely initiated in different locations near the inflating conduit, depending on the progression of deformation of the rock. Green and Neuberg (2006) also indicated that only minor evolution of the waveform was observed across the swarms in Soufrière Hills. In contrast, the gradual evolution of waveforms was recognized in some groups (Fig.13), 
which implies that gradual changes in the source location and the source mechanisms for each group and/or gradual change in the structure of the source region occurred, probably due to progressive fracturing and deformation of the shallow volcanic edifice (Umakoshi et al., 2008). The evolution of waveforms with time has also been observed at Redoubt Volcano, Alaska (Stephens and Chouet, 2001).

As shown in Fig. 2, Shimizu et al. (1997) identified the hypocenters of relatively large events using the master event method, although the hypocenters of numerous small events could not be determined. Comparing the events in each earthquake group with the hypocentral data, we obtained hypocentral distributions for events belonging to groups K1, K2, and C1 through C3 (Fig. 14). Focal mechanisms could be obtained for events belonging to groups K1, C1, and C3 (Fig. 15, Nos. 1-3), and their hypocenters are marked by Nos. 1-3 in Fig. 14. Fig. 14 also shows the location of the buried dike inferred by Yamashina and Shimizu (1999) from the ground deformation data. As the lower limit of the dike cannot be strictly constrained, we assume that it extended to the hypocentral depth, as shown by the dotted line. Hypocenters of K1 and K2, which were correlated with the tilt cycles, were distributed to the eastern side just beneath the crater. This distribution can be interpreted as a combination of tectonic stress and local stress. Analyzing focal mechanisms for volcano-tectonic earthquakes at Unzen, Umakoshi et al. (2001) showed that the tectonic stress at Unzen is dominated by strong N-S extension and the direction of the P-axis can easily change due to local stresses, such as magmatic pressure. When the conduit is inflating under this stress regime, earthquakes occur at the eastern and western sides of the conduit (Yamaoka, 1994). This interpretation is consistent with the fact that the focal mechanism of No. 1 (K1) has its P-axis trending to the conduit. However, few hypocenters were identified on the western side of the conduit, probably because the dike intrusion occurred west of the conduit. In contrast, 
hypocenters of $\mathrm{C} 1$ through $\mathrm{C} 3$, which were not always correlated with the tilt cycles, were distributed to the northern side of the dike. The focal mechanisms of No. 2 (C1) and No.3 (C3) have P-axes roughly trending to the dike, which can be explained by the compressional stress generated by the increasing thickness of the dike. This stress was likely strong enough to cancel the tectonic stress with N-S extension.

Fig. 16 illustrates the geometric relationships among the conduit, the dike and the focal areas. The model of magma ascent and dike intrusion proposed by Yamashina and Shimizu (1999) is reflected in this figure. The maximum and minimum principal stresses from the tectonic stress are shown by deviatoric stresses $\sigma_{1}(>0)$ and $\sigma_{3}(<0)$, respectively. $\sigma_{\mathrm{R}}$ is the local stress generated by increased pressure in the conduit, and $\sigma_{\mathrm{D}}$ is generated by thickening of the dike $(\Delta \mathrm{l})$. Both $\sigma_{\mathrm{R}}$ and $\sigma_{\mathrm{D}}$ have positive values. The magma began to pass through the source location of cyclic tilt on May 12. When the conduit was inflating, seismicity intensified on the eastern side of the conduit under the compressional stress $\sigma_{\mathrm{R}}+\sigma_{1}$. The majority of the small HF events that are correlated with the tilt cycles probably occurred in this area. Yamashina and Shimizu (1999) conjectured that the ascent in the magma column was obstructed by an impediment about $160 \mathrm{~m}$ deep on May 14. As the upward magma flow was stagnant, the western wall of the conduit broke as a result of excess magmatic pressure. A dike intrusion started to the west and then moved upward. Accompanying the dike intrusion, relatively large events occurred to the northern side of the dike because $\sigma_{\mathrm{D}}+\sigma_{3}$ exceeded $\sigma_{1}$. We assume that the events on the northern side of the dike occurred during the period when the dike thickness was increasing, but it is unclear why such earthquakes did not occur south of the dike. 


\section{Conclusions}

This study revealed the characteristics of an HF earthquake swarm associated with the dome extrusion at Unzen Volcano on May 20, 1991. HF seismicity intensified between May 12 and 26. The seismicity rate increased and decreased repeatedly with a period of 1 to $2 \mathrm{~h}$, which was correlated with the tilt cycles observed $680 \mathrm{~m}$ west of the crater. Periods of high seismicity coincided with periods of craterward uplift. In contrast, when the craterward ground was subsiding, the seismicity rate was much lower. It is assumed that the cyclic tilt is caused by repeated inflation and deflation of the conduit and the HF earthquakes represent brittle failure of the stiff rock near the conduit.

Defining an earthquake group as a series of earthquakes with waveforms that are similar or vary only slightly over time, we identified ten earthquake groups from station FG3 $(0.5 \mathrm{~km}$ from the crater), two from station KRA $(3.5 \mathrm{~km})$, and three from station CJA $(8.7 \mathrm{~km})$. The groups recorded at FG3 include numerous small events, whereas those recorded at KRA and CJA include only relatively large events. Among these groups, eight groups at FG3 were correlated with the cyclic tilt and were classified into two types based on their duration $(<10 \mathrm{~min}$ or $>30 \mathrm{~min})$ in each cycle. When both types of groups appeared concurrently, the order of initiation in each cycle remained constant. Gradual evolution of waveforms was found in some groups, implying gradual changes in the source location and the source mechanisms for each group and/or gradual change in the structure of the source region.

Two groups recorded at KRA were correlated with the tilt cycles, while three groups recorded at CJA did not always show such a correlation. Hypocenters for the groups recorded at KRA were distributed on the eastern side of the conduit, which can be interpreted as a combination of tectonic stress with $\mathrm{N}-\mathrm{S}$ extension and local stress generated by the inflation of the conduit. The groups recorded at CJA occurred to the 
north of the dike trending westward from the conduit. The focal mechanisms have P-axes roughly trending to the dike, which can be explained by the compressional stress generated by the increasing thickness of the dike.

In order to verify our model for the cyclic activity associated with the May 1991 dome extrusion, future work will focus on the earthquake rates and amplitudes (e.g. Hammer and Neuberg, 2009) and reveal the dynamical behavior of the HF earthquake swarm. Furthermore, we will expand the dynamical analysis to the entire period of lava extrusion to constrain the mechanism of cyclic activity at Unzen Volcano.

\section{Acknowledgments}

We wish to thank Professor Emeritus Kazuya Ohta of Kyushu University for his support and encouragement throughout this study. Special thanks are due to the late Norimichi Matsuwo for his effort in correcting the seismic data used in this study. We thank J. Neuberg and two anonymous reviewers for their helpful comments and suggestions that significantly improved the manuscript. This study was partly supported by the Unzen Scientific Drilling Project (USDP) funded by the Ministry of Education, Culture, Sports, Science and Technology, Japan and a Grant-in-Aid for Scientific Research funded by the Japan Society for the Promotion of Science. 


\section{References}

Barmin, A., Melnik, O., Sparks, R.S.J., 2002. Periodic behavior in lava dome eruptions. Earth Planet. Sci. Lett. 199, 173-184.

Denlinger, R.P., Hoblitt, R.P., 1999. Cyclic eruptive behavior of silicic volcanoes. Geology 27(5), 459-462

Fukuoka District Meteorological Observatory, 1996. Memoirs of Fukuoka Meteorological Observatory. No. 51, 315pp, in Japanese.

Garcia-Aristizabal, A., Kumagai, H., Samaniego, P., Mothes, P., Yepes, H., Monzier, M., 2007. Seismic, petrologic, and geodetic analyses of the 1999 dome-forming eruption of Guagua Pichincha volcano, Ecuador. J. Volcanol. Geotherm. Res. 161, 333-351.

Geophysical Party, Joint University Research Group, 1992. Geophysical observation of the 1990-1992 eruption at Unzen Volcano (Part 1), Bull. Volcanol. Soc. Jpn. 37, 209-215, in Japanese.

Green, D.N., Neuberg, J., 2006. Waveform classification of volcanic low-frequency earthquake swarms and its implication at Soufrière Hills Volcano, Montserrat. J. Volcanol. Geotherm. Res. 153, 51-63.

Hamaguchi, H., Hasegawa, A., 1975. Recurrent occurrence of the earthquakes with similar wave forms and its related problems. J. Seismol. Soc. Japan, Ser. 2, 28, 153-169. in Japanese.

Hammer, C., Neuberg, J.W., 2009. On the dynamical behaviour of low-frequency earthquake swarms prior to a dome collapse of Soufrière Hill volcano, Montserrat. Geophys. Res. Lett., 36, L06305, doi:10.1029/2008GL036837.

Miller, A.D., Stewart, R.C., White, R.A., Luckett, R., Baptie, B.J., Aspinall, W.P., Latchman, J.L., Lynch, L.L., Voight, B., 1998. Seismicity associated with dome growth and collapse at the Soufriere Hills Volcano, Montserrat. Geophys. Res. Lett. 
25(18), 3401-3404.

Nagaoka, M., Kumaki, Y., Chiba, T., 1996. Measurements of lava effusion rate and total volume of products at Fugendake, Unzen volcano. Monthly Chikyu Spec. 15, 60-63, in Japanese.

Nakada, S., Shimizu, H., Ohta, K., 1999. Overview of the 1990-1995 eruption at Unzen Volcano. J. Volcanol. Geotherm. Res. 89, 1-22.

Neuberg, J.W., Tuffen, H., Collier, L., Green, D., Powell, T., Dingwell, D., 2006. The trigger mechanism of low-frequency earthquakes on Montserrat. J. Volcanol. Geotherm. Res. 153, 37-50.

Ohta, K., 1993. The 1990-1992 eruptive activity at Unzen Volcano. J. Geol. Soc. Jpn. 99, 835-854, in Japanese.

Okada, Hm., Watanabe, H., Yamashita, H., Yokoyama, I., 1981. Seismological significance of the 1977-1978 eruptions and the magma intrusion process of Usu Volcano, Hokkaido. J. Volcanol. Geotherm. Res. 9, 311-334.

Power, J.A., Lahr, J.C., Page, R.A., Chouet, B.A., Stephens, C.D., Harlow, D.H., Murray, T.L., Davies, J.N., 1994. Seismic evolution of the 1989-1990 eruption sequence of Redoubt Volcano, Alaska. J. Volcanol. Geotherm. Res. 62, 69-94.

Saito, E., Suto, S., Soya, T., Kazahaya, K., Kawanabe, Y., Hoshizumi, H., Watanabe, K., Endo, H., 1993. Geodetic monitoring using EDM before and during the 1991-1992 lava extrusion of Fugen-dake, Unzen Volcano, Kyushu, Japan. Bull. Geol. Surv. Jpn. 44, 639-647, in Japanese.

Shimizu, H., Umakoshi, K., Matsuwo, N., Ohta, K., 1992. Seismological observations of Unzen Volcano before and during the 1990-1992 eruption, In: Yanagi, T., Okada, H., Ohta, K. (Eds.), Unzen Volcano, The 1990-1992 Eruption. The Nishinippon and Kyushu University Press, pp. 38-43. 
Shimizu, H., Umakoshi, K., Matsuwo, N., Matsushima, T., Ohta, K., 1997. Seismic activity associated with the magma ascent and dome growth of Unzen Volcano. Unzen international workshop: decade volcano and scientific drilling, Proceedings, pp. $42-44$.

Stephens, C.D, Chouet, B.A., 2001. Evolution of the December 14, 1989 precursory long-period event swarm at Redoubt Volcano, Alaska. J. Volcanol. Geotherm. Res. 109, 133-148.

Sudo, Y., Tsutsui, T., Sako, M., Masuda, H., Hoka, T., Yamada, T., 1992. Seismic observation at Nodake, Unzen Volcano. In: Ohta, K.(Ed.), Research on the prediction of lava extrusion at Unzen Volcano. Rep. Aid. Sci. Res., Kyushu Univ., pp.21-28, in Japanese.

Tanaka, Y., Hashimoto, T., Masuda, H., Yoshikawa, S., Joint Group of University for Electromagnetic Research, 1994. Volcano-magnetic effects on the Unzen Volcano (1991-1993). Ann. Disas. Prev. Res. Inst., Kyoto Univ. 37, B-1, 193-206, in Japanese.

Umakoshi, K., Shimizu, H., Matsuwo, N., 2001. Volcano-tectonic seismicity at Unzen Volcano, Japan, 1985-1999. J. Volcanol. Geotherm. Res. 112, 117-131.

Umakoshi, K., Shimizu, H., Matsuwo, N., 2002. Seismic activity associated with the growth of the lava dome at Unzen Volcano (November 1993-January 1994) -grouping of earthquakes on the basis of cross-correlations among their waveforms-. Bull. Volcanol. Soc. Jpn. 47, 43-55, in Japanese.

Umakoshi, K., Takamura, N., Shinzato, N., Uchida, K., Matsuwo, N., Shimizu, H., 2008. Seismicity associated with the 1991-1995 dome growth at Unzen Volcano, Japan. J. Volcanol. Geotherm. Res. 175, 91-99.

Voight, B., Hoblitt, R.P., Clarke, A.B., Lockhart, A.B., Miller, A.D., Lynch, L., McMahon, 
J., 1998. Remarkable cyclic ground deformation monitored in real-time on Montserrat, and its use in eruption forecasting. Geophys. Res. Lett. 25(18), $3405-3408$.

Voight, B., Sparks, R.S.J., Miller, A.D., Stewart, R.C., Hoblitt, R.P., Clarke, A., Ewart, J., Aspinall, W.P., Baptie, B., Calder, E.S., Cole, P., Druitt, T.H., Hartford, C., Herd, R.A., Jackson, P., Lejeune, A.M., Lockhart, A.B., Loughlin, S.C., Luckett, R., Lynch, L., Norton, G.E., Robertson, R., Watson, I.M., Watts, R., Young, S.R., 1999. Magma flow instability and cyclic activity at Soufriere Hills Volcano, Montserrat, British West Indies, Science 283, 1138-1142.

Watanabe, H., 1971. Determination of earthquake magnitude at regional distance in and near Japan. J. Seismol. Soc. Japan, Ser. 2, 24, 189-200, in Japanese.

Yamaoka, K., 1994. On the relationship between volcanic activity and earthquakes from the viewpoint of crustal stress with special reference to the activity in Izu-Oshima Volcano, Japan. Bull. Volcanol. Soc. Jpn. 39, 141-153, in Japanese.

Yamashina, K., 1995. Cyclic supply of lava suggested by the hourly oscillation of tilt at Unzen volcano, Japan. Proc. '95 Int. Workshop Volcanoes Commem. 50th Anniv. Mt. Showa-Shinzan, pp.208-209.

Yamashina, K., Shimizu, H., 1999. Crustal deformation in the mid-May 1991 crisis preceding the extrusion of a dacite lava dome at Unzen volcano, Japan. J. Volcanol. Geotherm. Res. 89, 43-55.

Yasuda, A., Suto, S., Endo, H., 1993. Ground deformation of Unzen volcano during the 1991 eruption as measured by aerial photograph analysis. Bull. Geol. Surv. Jpn. 44, 631-637, in Japanese. 


\section{Captions}

Table 1

Daily number of high-frequency (HF) and low-frequency (LF) earthquakes and pyroclastic flows (PF). Pyroclastic flow data were obtained from the Fukuoka District Meteorological Observatory (1996).

\begin{tabular}{|c|c|c|c|}
\hline Day & $\mathrm{HF}$ & $\mathrm{LF}$ & PF \\
\hline 11 & 86 & 3 & - \\
\hline 12 & 1081 & 63 & - \\
\hline 13 & 1123 & 46 & - \\
\hline 14 & 1464 & 20 & - \\
\hline 15 & 1793 & 12 & - \\
\hline 16 & 2426 & 14 & - \\
\hline 17 & 2760 & 18 & - \\
\hline 18 & 2722 & 14 & - \\
\hline 19 & 2163 & 14 & - \\
\hline 20 & 1937 & 10 & - \\
\hline 21 & 1875 & 610 & - \\
\hline 22 & 1832 & 899 & - \\
\hline 23 & 1991 & 125 & - \\
\hline 24 & 1664 & 186 & 5 \\
\hline 25 & 1503 & 186 & 4 \\
\hline 26 & 960 & 173 & 25 \\
\hline 27 & 534 & 270 & 34 \\
\hline 28 & 398 & 152 & 5 \\
\hline 29 & 566 & 138 & 31 \\
\hline 30 & 300 & 303 & 24 \\
\hline 31 & 223 & 257 & 15 \\
\hline Total & 29,401 & 3513 & 143 \\
\hline
\end{tabular}


Table 2

Active period, duration (h), and number of events for each earthquake group identified in this study. F1 through $\mathrm{F} 10, \mathrm{~K} 1$ and $\mathrm{K} 2$, and $\mathrm{C} 1$ through $\mathrm{C} 3$ were identified from waveform data recorded at stations FG3, KRA, and CJA, respectively.

\begin{tabular}{lclccc}
\hline Name & \multicolumn{1}{c}{ Period (day / hour:minute) } & Duration(h) & Number \\
\hline F1 & $12 / 14: 59$ & - & $13 / 02: 45$ & 12 & 300 \\
F2 & $13 / 12: 50$ & - & $14 / 08: 28$ & 20 & 328 \\
F3 & $13 / 07: 22$ & - & $17 / 01: 43$ & 90 & 433 \\
F4 & $13 / 21: 04$ & - & $31 / 23: 31$ & 434 & 3214 \\
F5 & $14 / 14: 01$ & - & $18 / 16: 51$ & 99 & 2070 \\
F6 & $15 / 21: 44$ & - & $27 / 07: 23$ & 274 & 1161 \\
F7 & $16 / 12: 33$ & - & $30 / 09: 01$ & 332 & 1245 \\
F8 & $17 / 14: 37$ & - & $19 / 12: 34$ & 46 & 879 \\
F9 & $18 / 11: 05$ & - & $21 / 14: 06$ & 75 & 556 \\
F10 & $19 / 01: 10$ & - & $27 / 16: 38$ & 207 & 632 \\
K1 & $14 / 00: 02$ & - & $31 / 06: 10$ & 414 & 722 \\
K2 & $18 / 16: 53$ & - & $28 / 00: 24$ & 224 & 186 \\
C1 & $14 / 10: 08$ & - & $30 / 03: 05$ & 377 & 90 \\
C2 & $18 / 12: 22$ & - & $21 / 11: 43$ & 71 & 15 \\
C3 & $19 / 21: 28$ & - & $30 / 06: 23$ & 249 & 18 \\
& & & & & \\
\hline
\end{tabular}




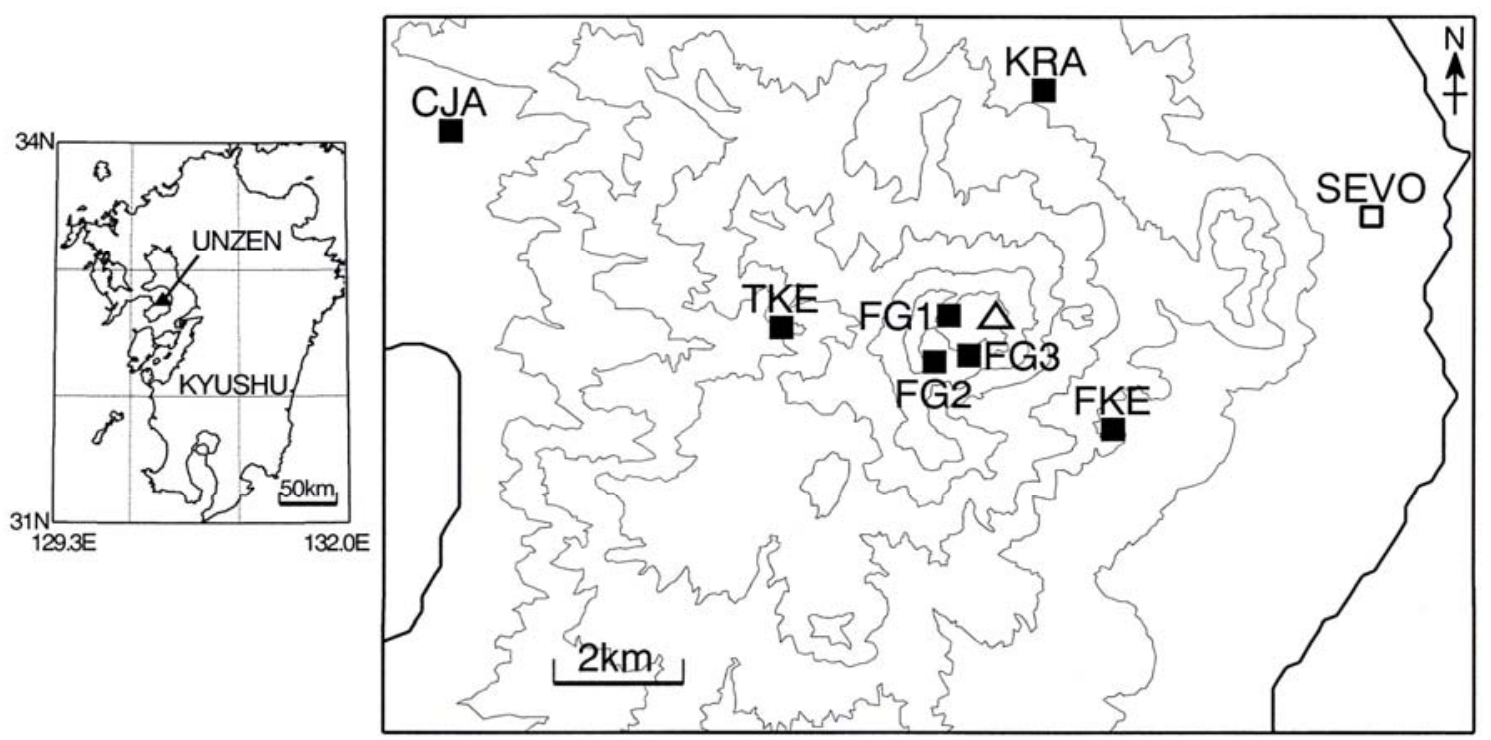

Fig. 1. Map showing locations of the seismic stations (closed squares) installed by the Shimabara Earthquake and Volcano Observatory (SEVO) of Kyushu University. Data from stations FG3, KRA, and CJA were used in this study. Stations FG1, FG2, FG3, TKE, FKE, and KRA were used for hypocentral determination by Shimizu et al. (1997). The open square denotes the location of SEVO. The open triangle indicates the location of Jigokuato Crater, where the lava dome emerged on May 20, 1991. The contour interval is $200 \mathrm{~m}$. 

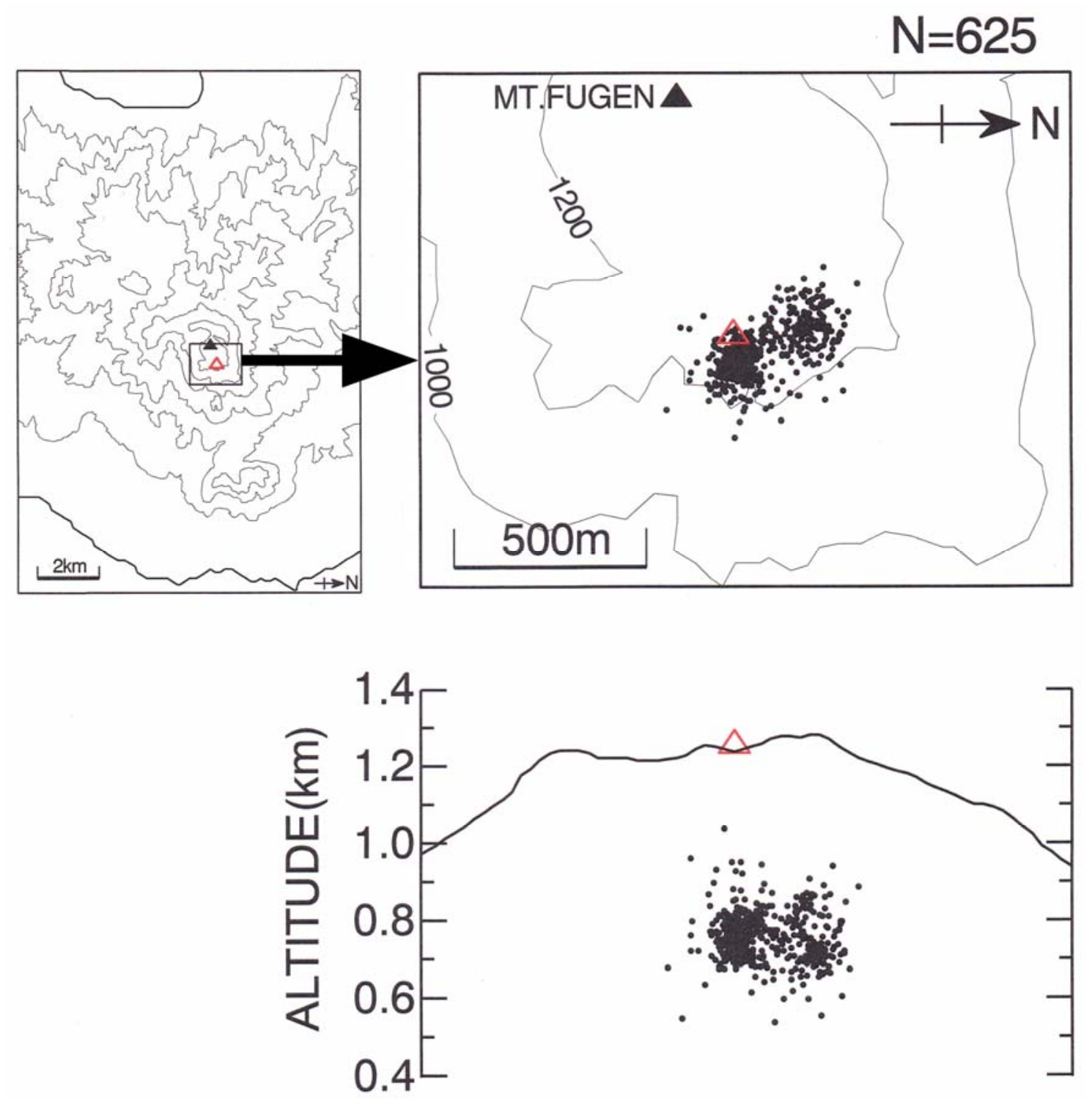

Fig. 2. Map and N-S cross-section of earthquakes in May 1991 (Shimizu et al., 1997). Only earthquakes with P-wave RMS travel-time residuals less than $0.03 \mathrm{~s}$ are shown. The open triangle indicates the location of Jigokuato Crater. 

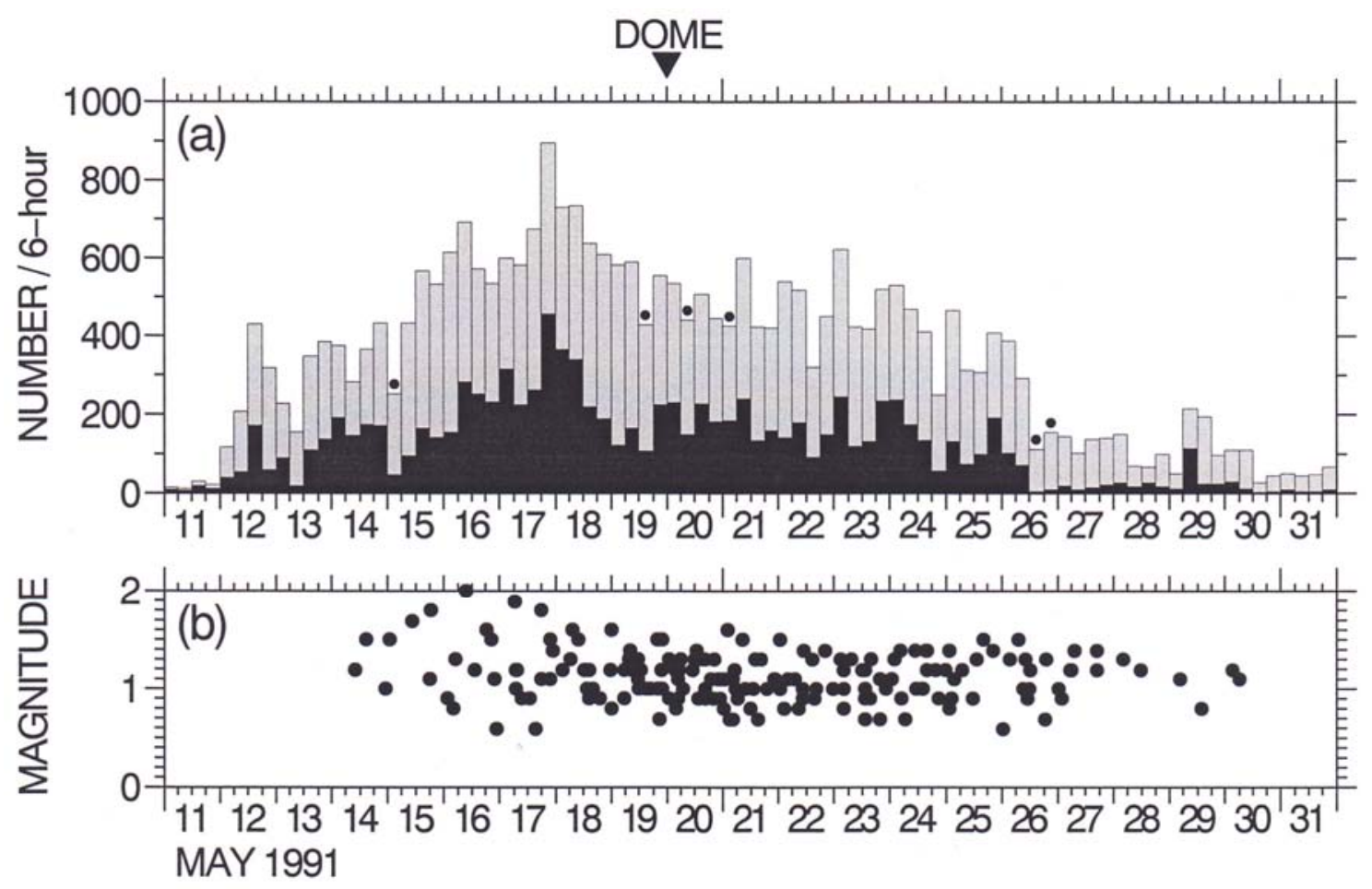

Fig. 3. (a) Number of HF events in 6-h intervals. Black bars indicate the number of events with maximum amplitudes $\geq 3 \times 10^{-5} \mathrm{~m} / \mathrm{s}$, and gray bars show those between $1 \mathrm{x}$ $10^{-5}$ and $3 \times 10^{-5} \mathrm{~m} / \mathrm{s}$. Small closed circles above the bars indicate that the total numbers of earthquakes were reduced because the seismograms were disturbed by debris flows caused by heavy rainfall. (b) Plots of magnitude versus time for 182 events selected at CJA. 

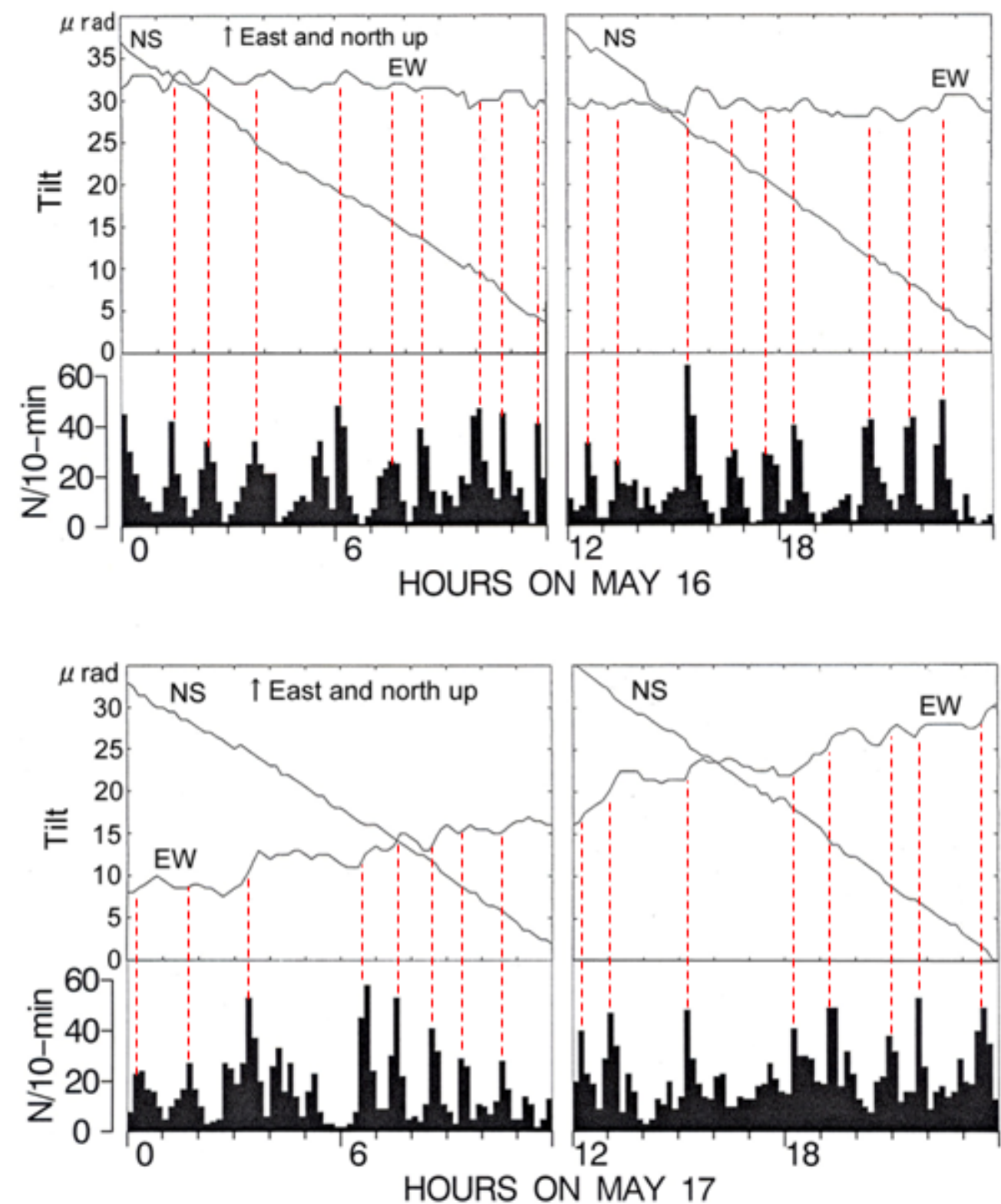

Fig. 4. Tilt records for the E-W and N-S components in microradians, observed $680 \mathrm{~m}$ west of the crater (Yamashina and Shimizu, 1999) and the number of HF events at 10-min intervals (May 16 to 17, 1991). Dotted vertical lines indicate earthquake count peaks. 


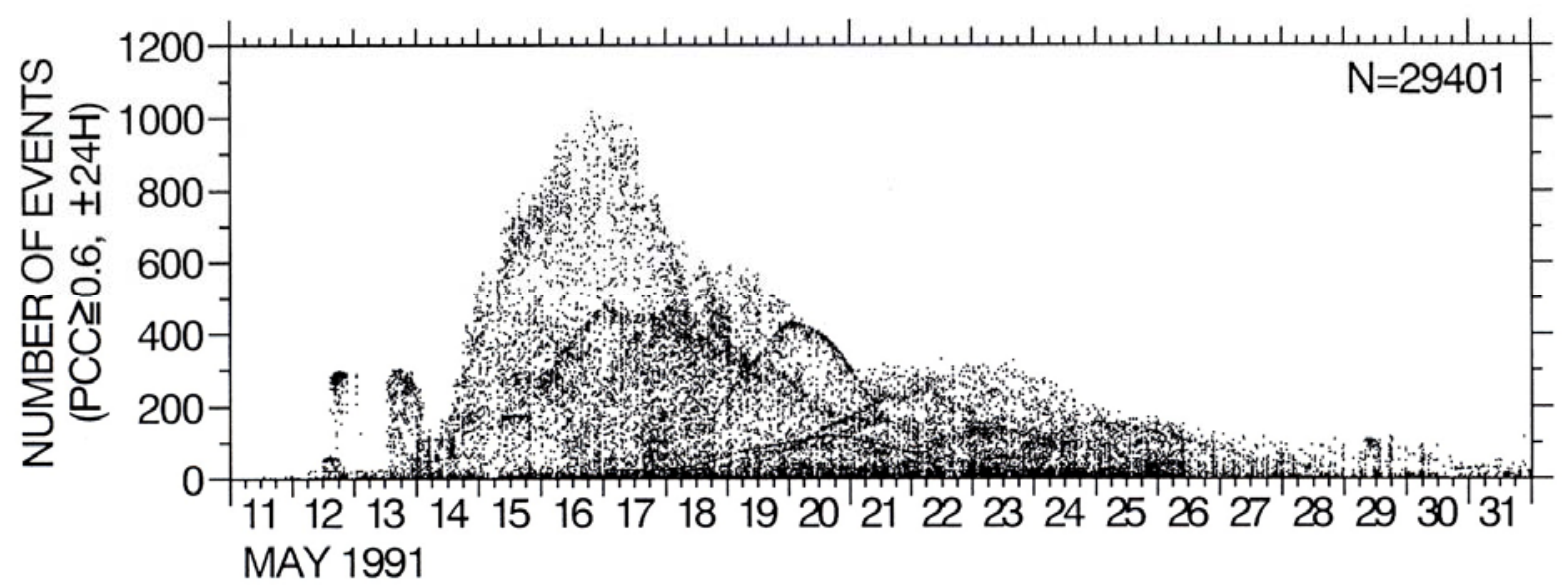

Fig. 5. Number of events with peak cross-correlation coefficients (PCCs) $\geq 0.6$ within 24 $\mathrm{h}$ before and after each reference event. All events were used individually as reference events. The horizontal axis is the occurrence time of reference events. 

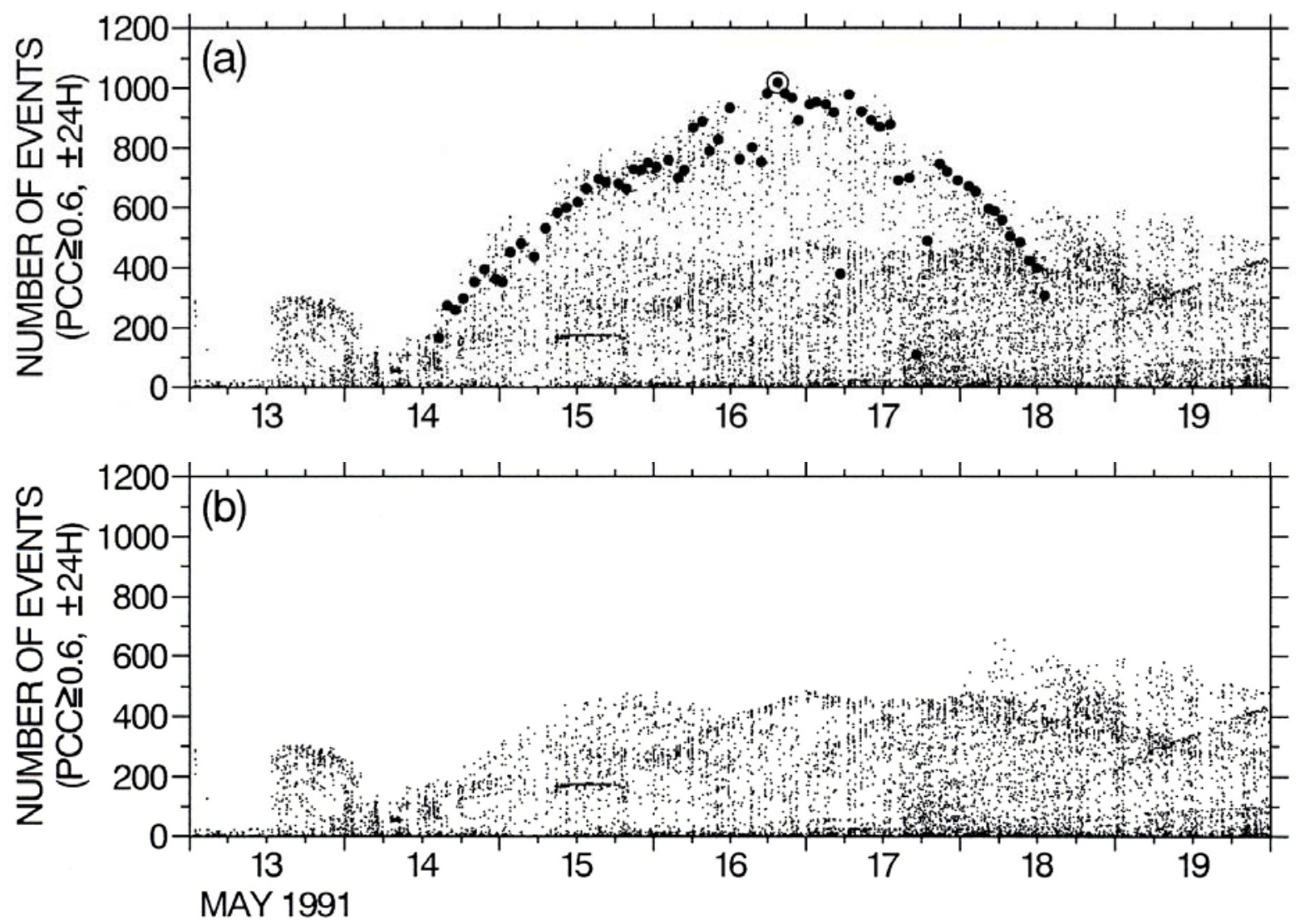

Fig. 6. (a) Enlargement of part of Fig. 5 for May 13 to 19, 1991. The double circle indicates the initial reference event used for identifying an earthquake group. The closed circles indicate the reference events derived from the initial reference event. These were used to extract events for an earthquake group. (b) Results after removing a group of events identified in (a). 


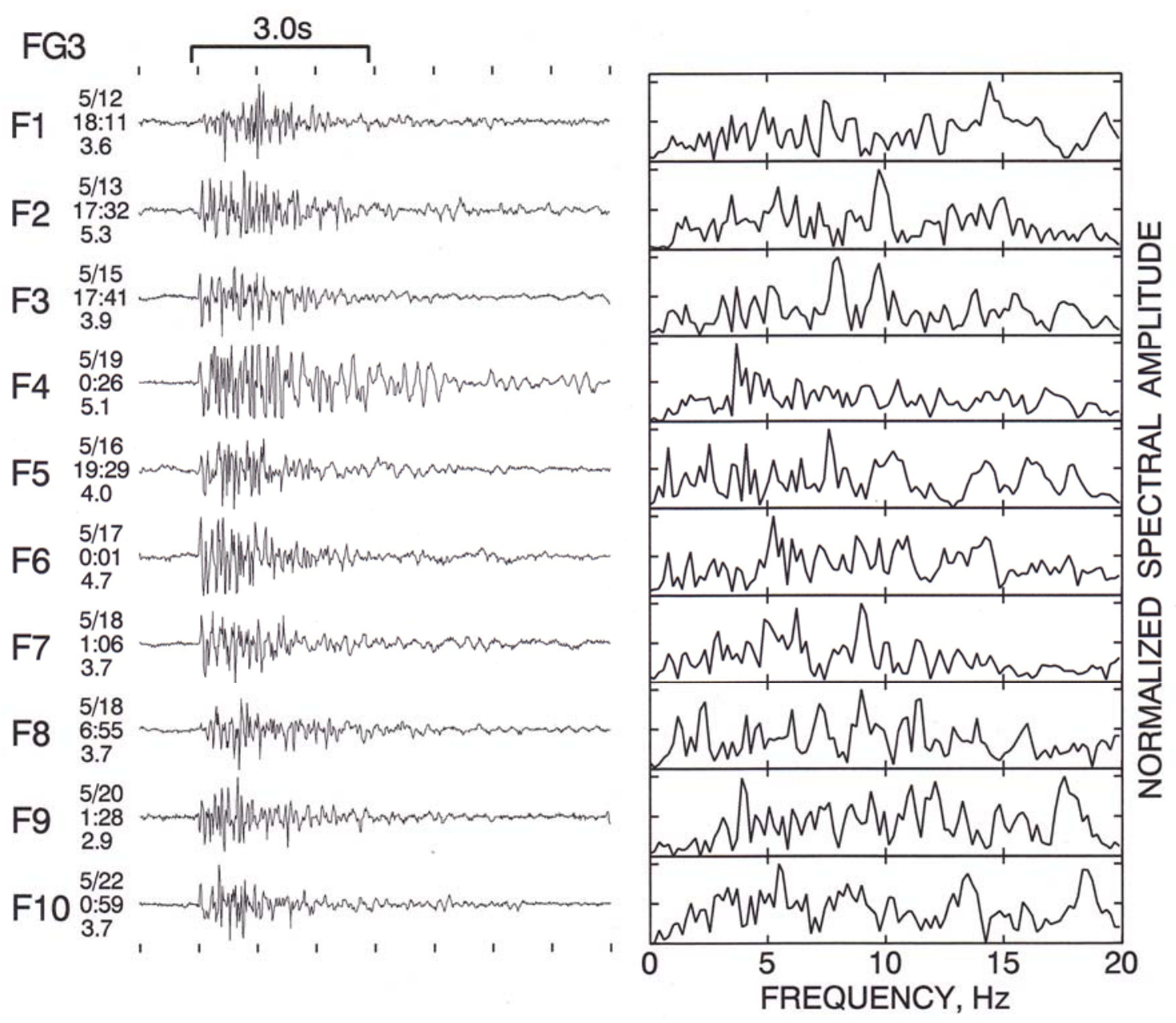

Fig. 7. Seismograms of the initial reference events and normalized spectral amplitude for groups F1 through F10. Waveforms are normalized to the relevant maximum amplitude. The top, middle, and bottom numbers on the left side of each waveform indicate the month/day, hour:minute, and maximum amplitude $\left(\mathrm{x} 10^{-5} \mathrm{~m} / \mathrm{s}\right)$, respectively. The window length for calculation of cross-correlation coefficients is shown at the top. 


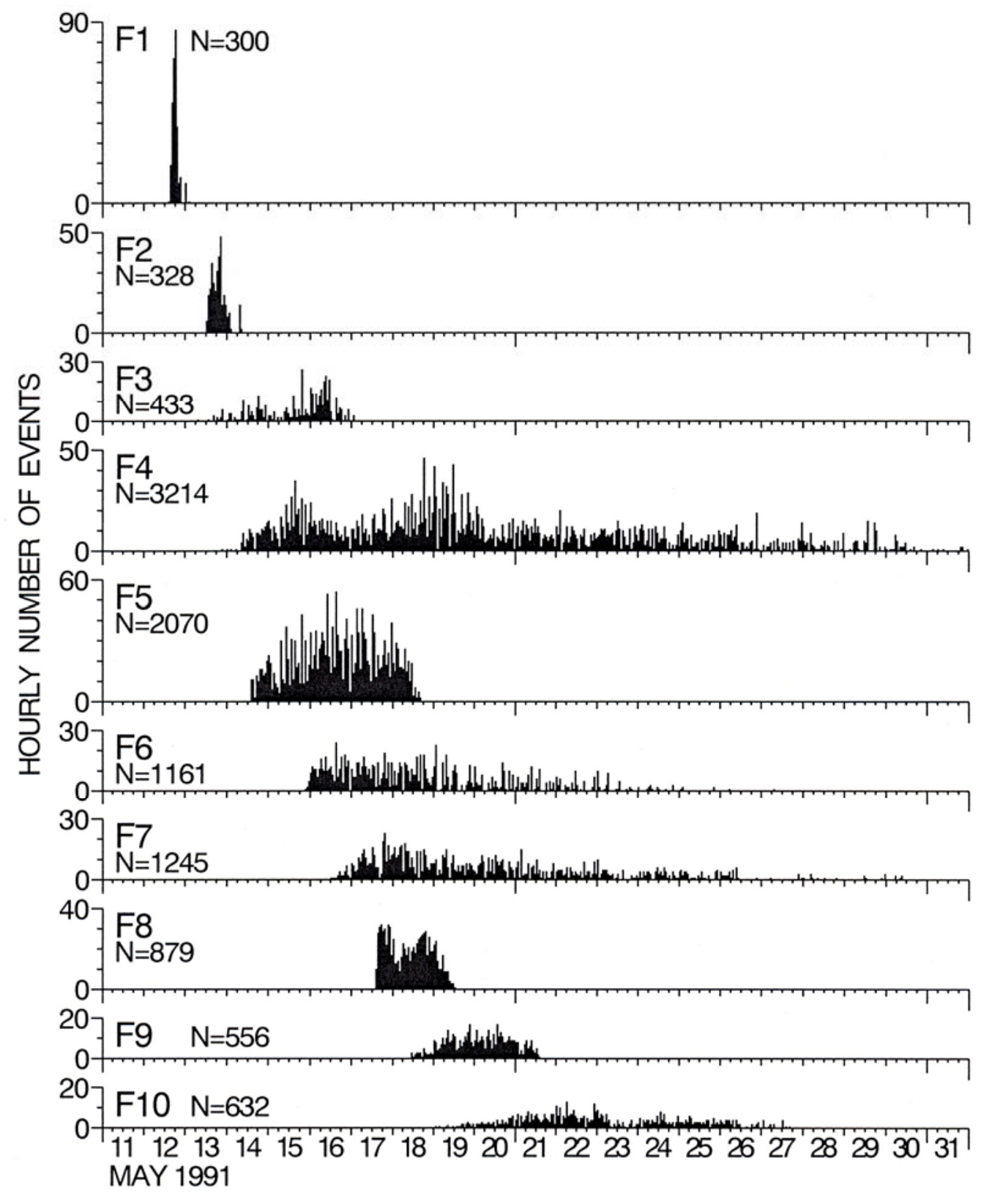

Fig. 8. Hourly number of events for groups F1 through F10. 

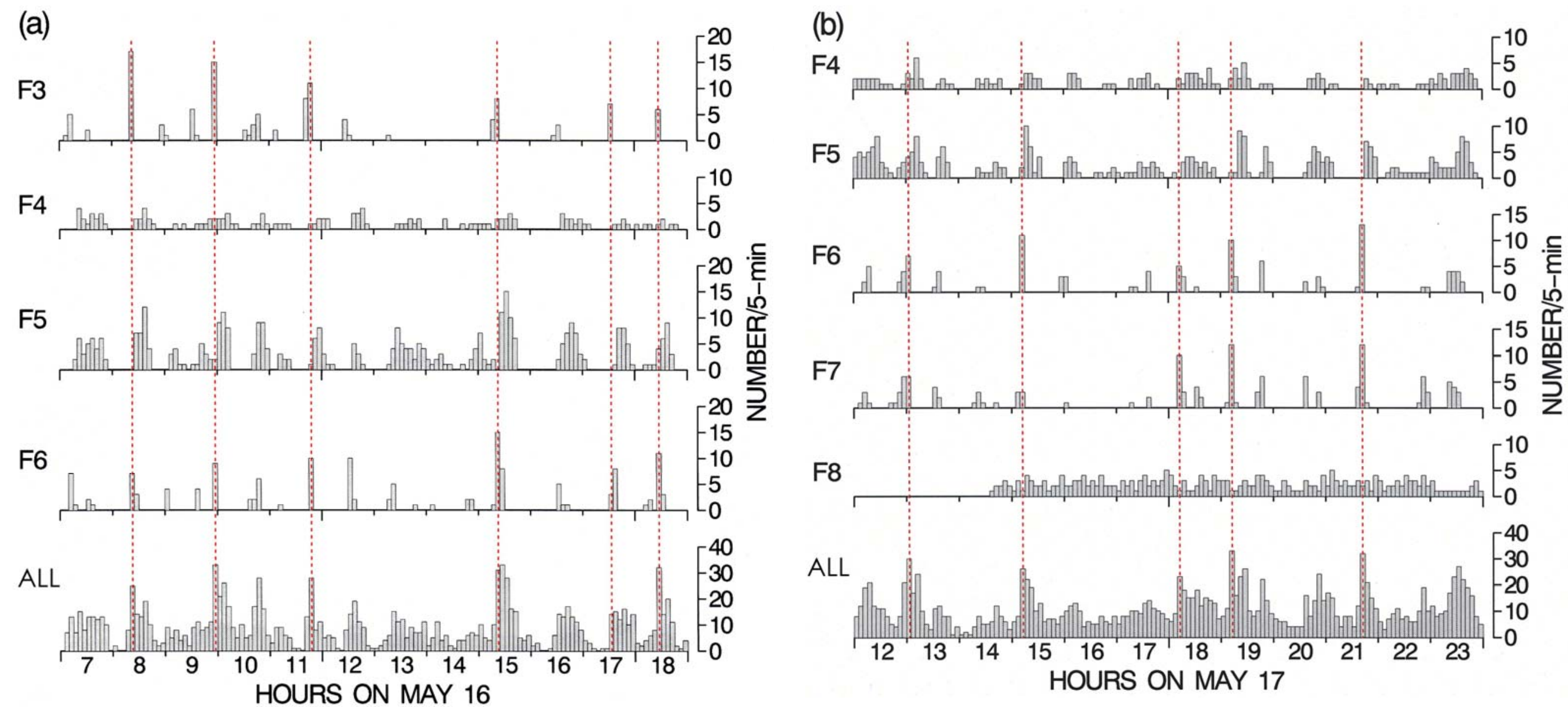

Fig. 9. Number of events in 5-min intervals for each earthquake group and all HF events. (a) 07:00 to 18:59 on May 16; (b) 12:00 to 23:59 on May 17. The vertical dotted lines are drawn on the count peaks for group F3 or F6. 

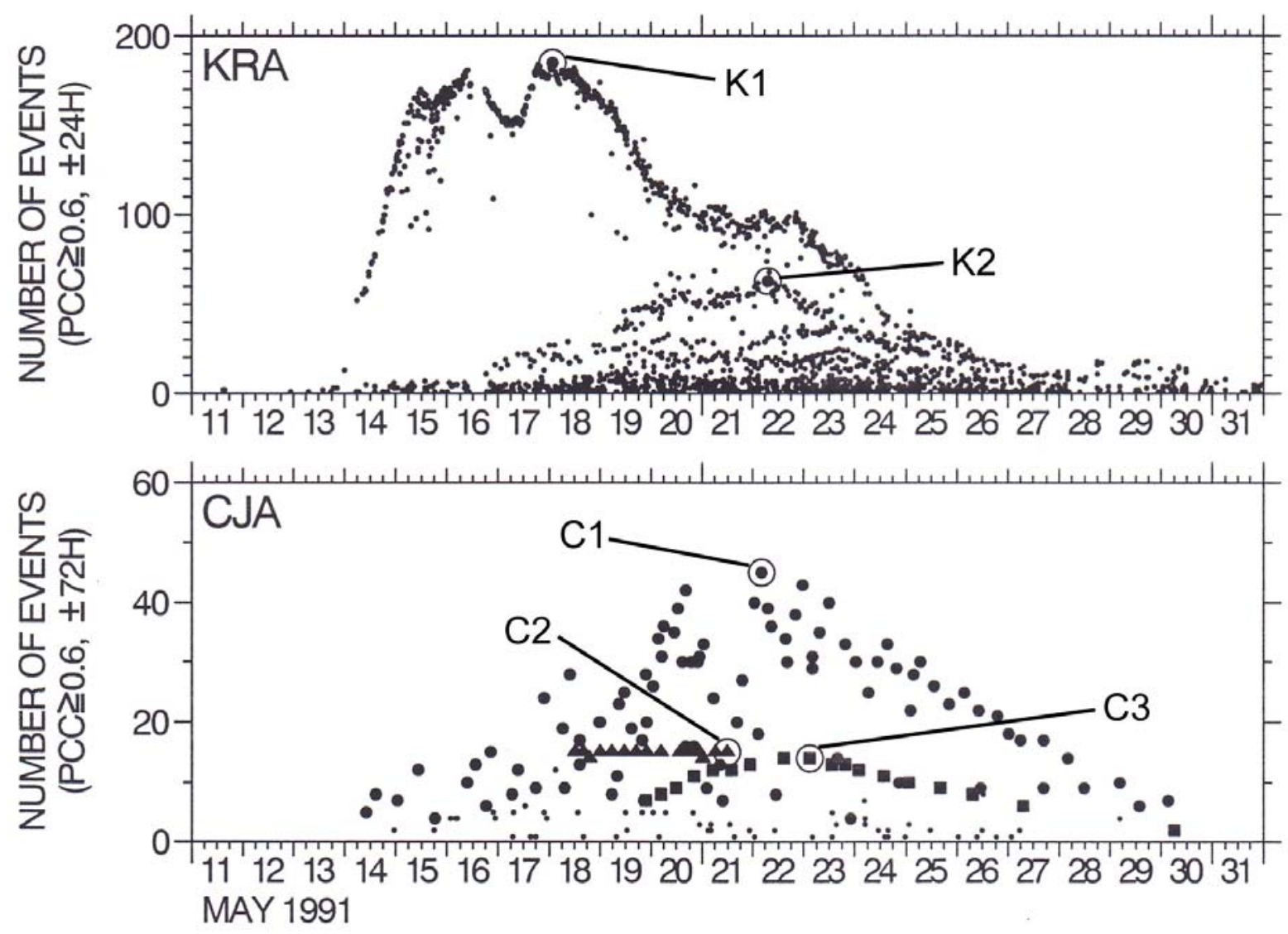

Fig. 10. Number of events with PCCs $\geq 0.6$ within $24 \mathrm{~h}$ (top, station KRA) or $72 \mathrm{~h}$ (bottom, station CJA) before and after each reference event. The open circles indicate the initial reference events used for identifying earthquake groups $\mathrm{K} 1, \mathrm{~K} 2$, and $\mathrm{C} 1$ through C3. In the bottom figure, closed circles, triangles, and squares indicate the events belonging to groups $\mathrm{C} 1, \mathrm{C} 2$, and $\mathrm{C} 3$, respectively, as a result of identifying groups. 

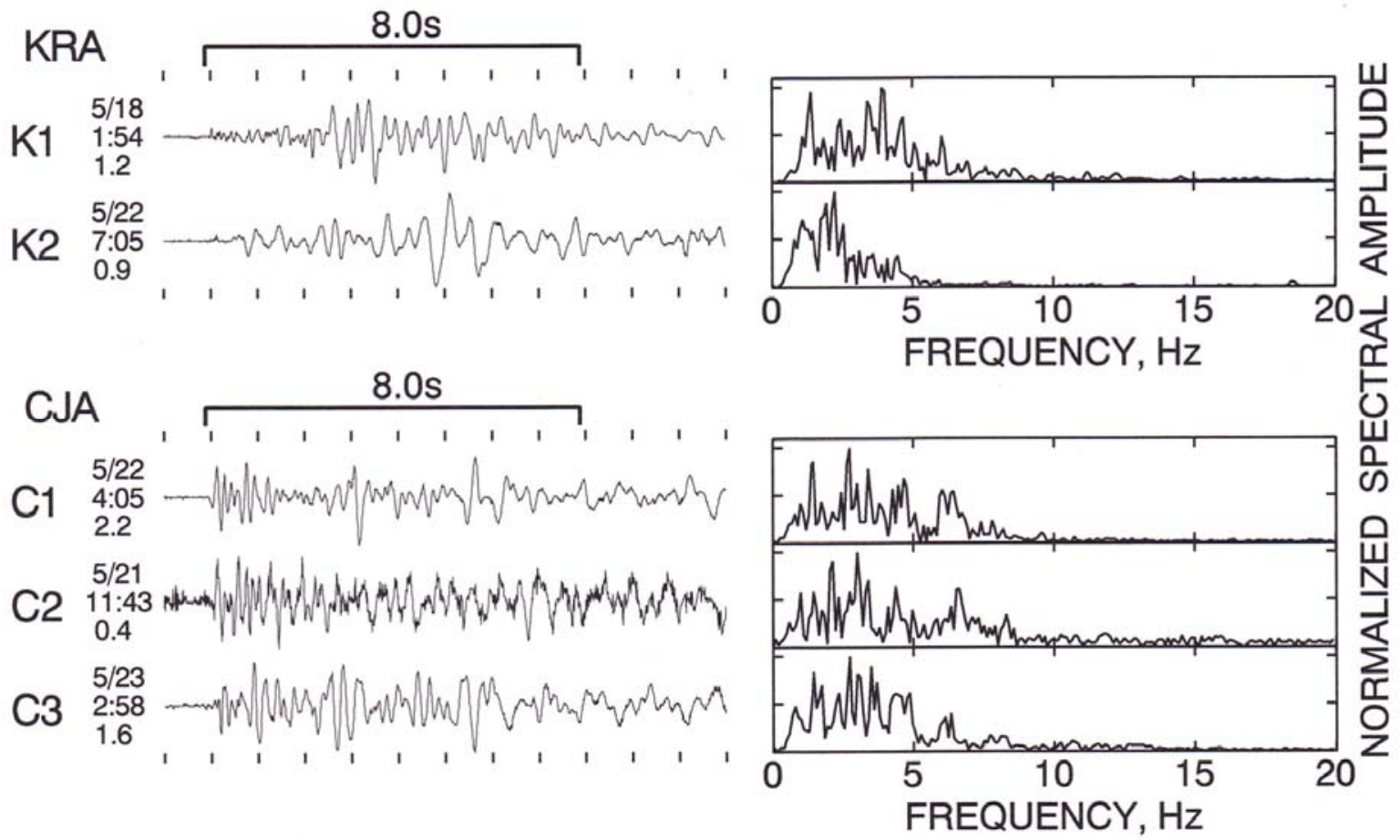

Fig. 11. Seismograms for the initial reference events and normalized spectral amplitude for groups $\mathrm{K} 1, \mathrm{~K} 2$, and $\mathrm{C} 1$ through $\mathrm{C} 3$. The numbers on the left are the same as those in Fig. 7. 

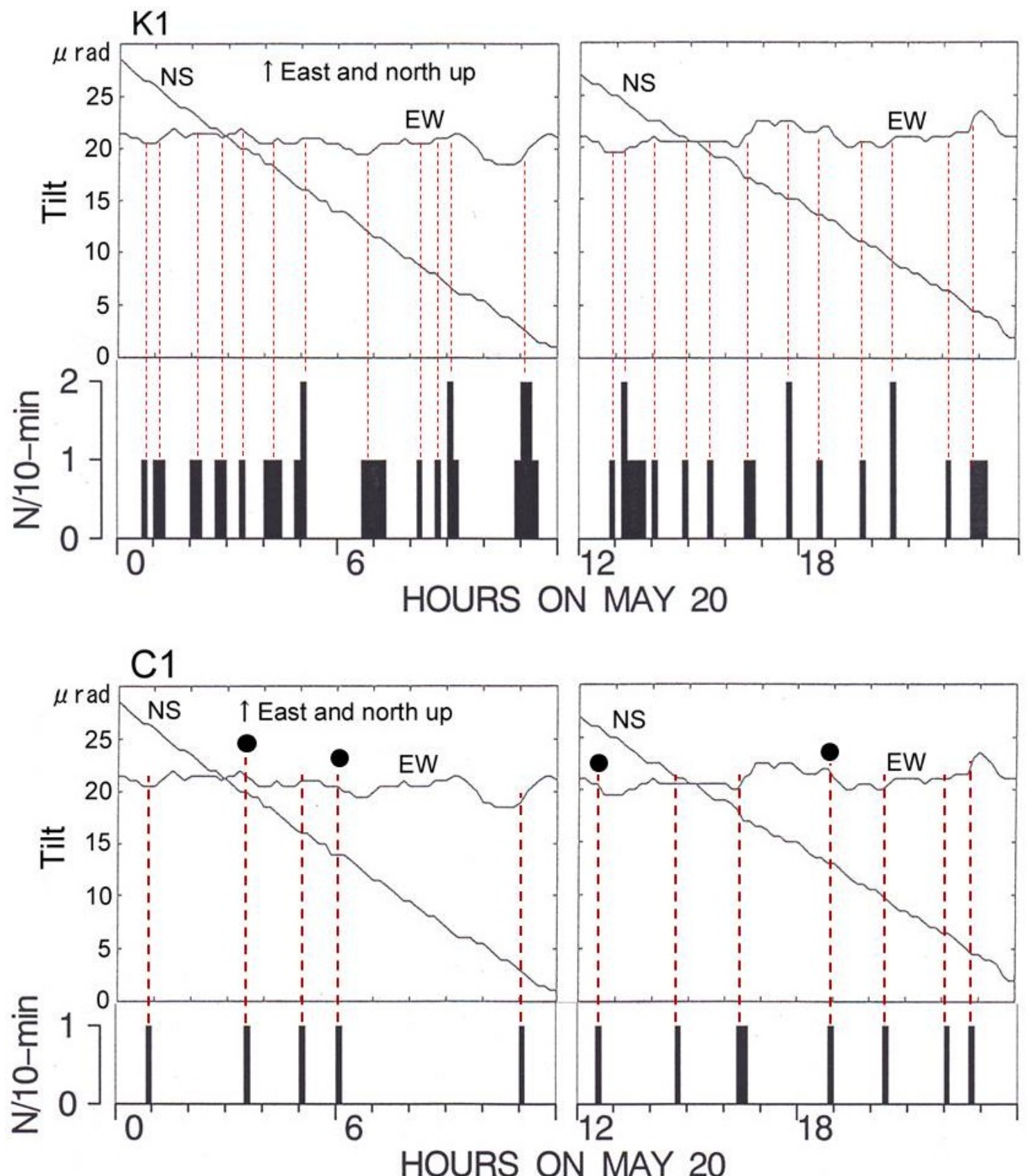

Fig. 12. Tilt variations (Yamashina and Shimizu, 1999) and the number of events at 10-min intervals for groups K1 and C1 on May 20, 1991. The closed circles above the vertical dotted lines in $\mathrm{C} 1$ indicate that the earthquakes occurred during eastward subsidence. 


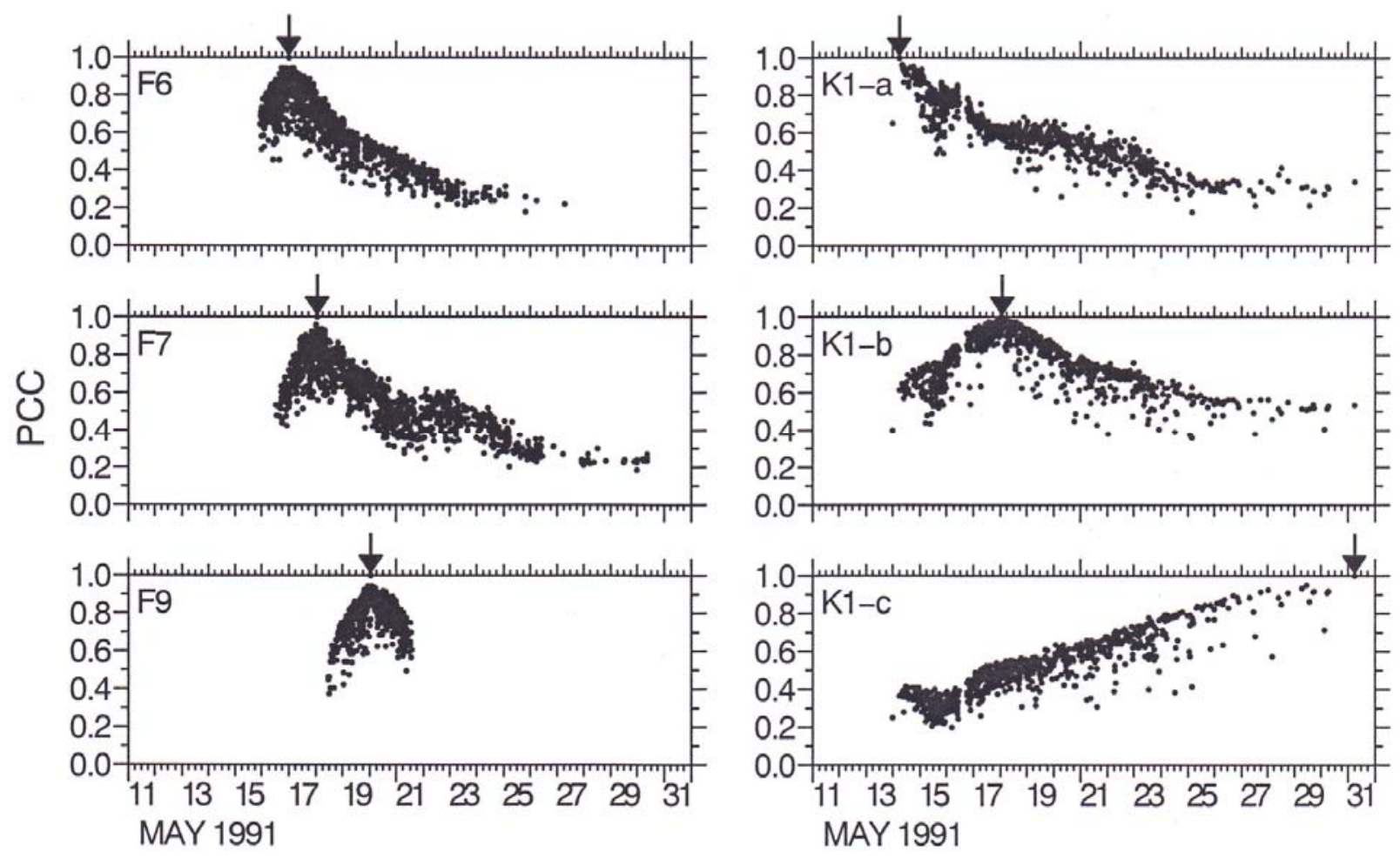

Fig. 13. PCCs for the waveforms in groups F6, F7, F9, and K1. In each case, the time of the reference event is indicated by an arrow at the top of the figure. For K1, three different reference events were used and the results are shown in K1-a, K1-b, and K1-c. 

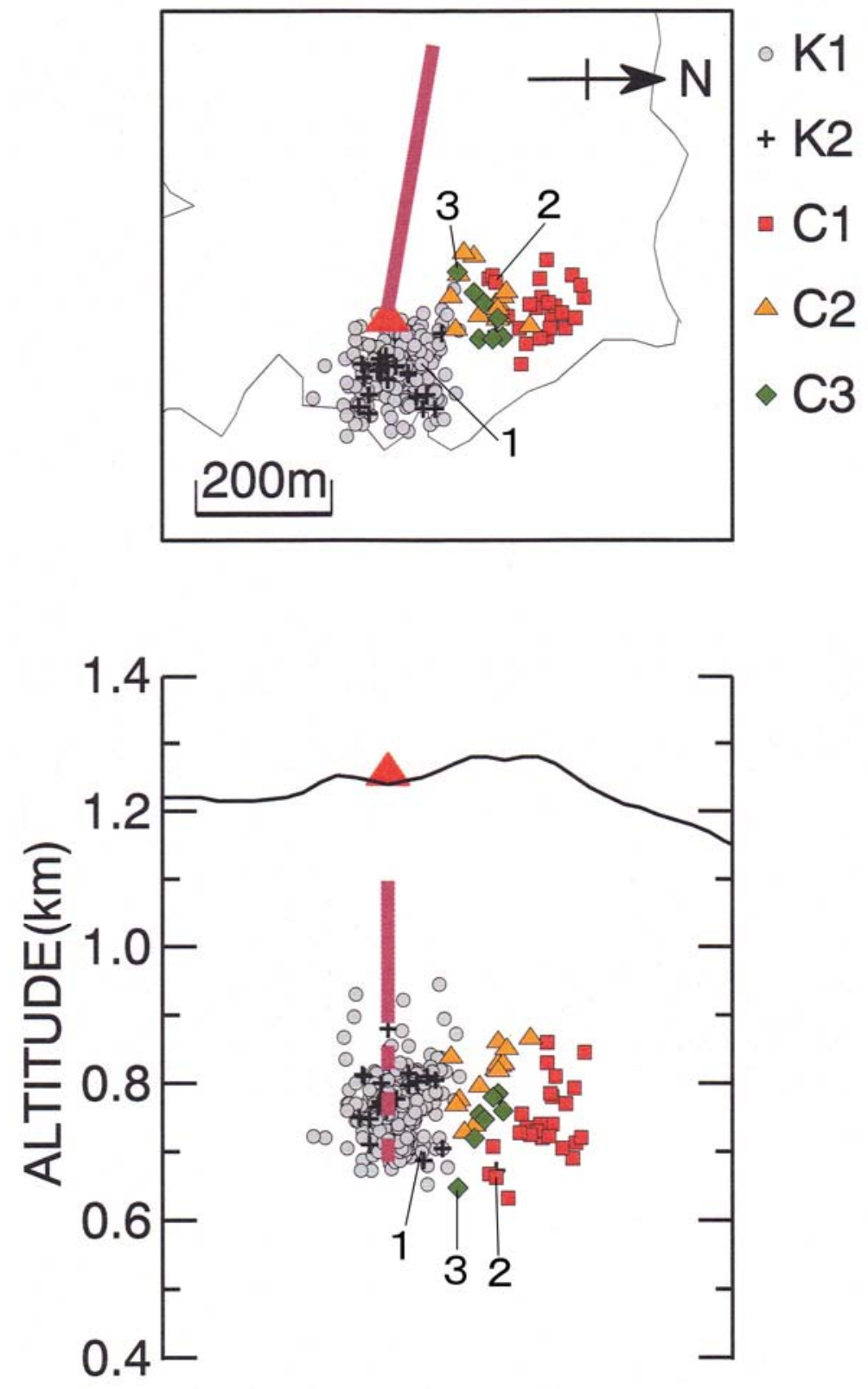

Fig. 14. Map and N-S cross section of earthquakes in groups K1, K2, and C1 through C3. The closed triangles indicate the location of Jigokuato Crater. The rectangles indicate the location of the buried dike proposed by Yamashina and Shimizu (1999). Hypocenters marked as Nos. 1-3 correspond to the focal mechanisms in Fig. 15. 
(1) 01:26 MAY 16, 1991

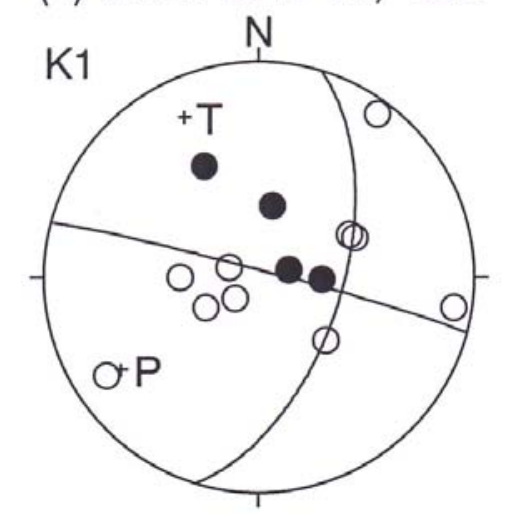

(2) 00:51 MAY 15, 1991

(3) 02:58 MAY 23, 1991
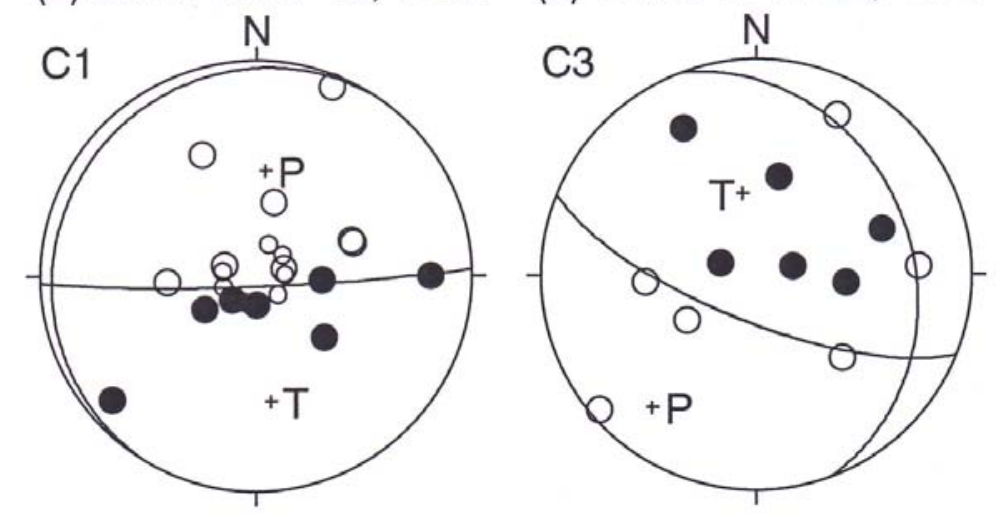

Fig. 15. Focal mechanisms for events in groups K1, C1, and C3 (Nos. 1-3). The diagrams are shown by equal area projection on the lower hemisphere; closed and open circles denote compression and dilatation, respectively. Pluses with $\mathrm{P}$ and $\mathrm{T}$ denote the positions of the P- and T-axes. The hypocenter locations are shown by Nos. 1-3 in Fig. 14. 


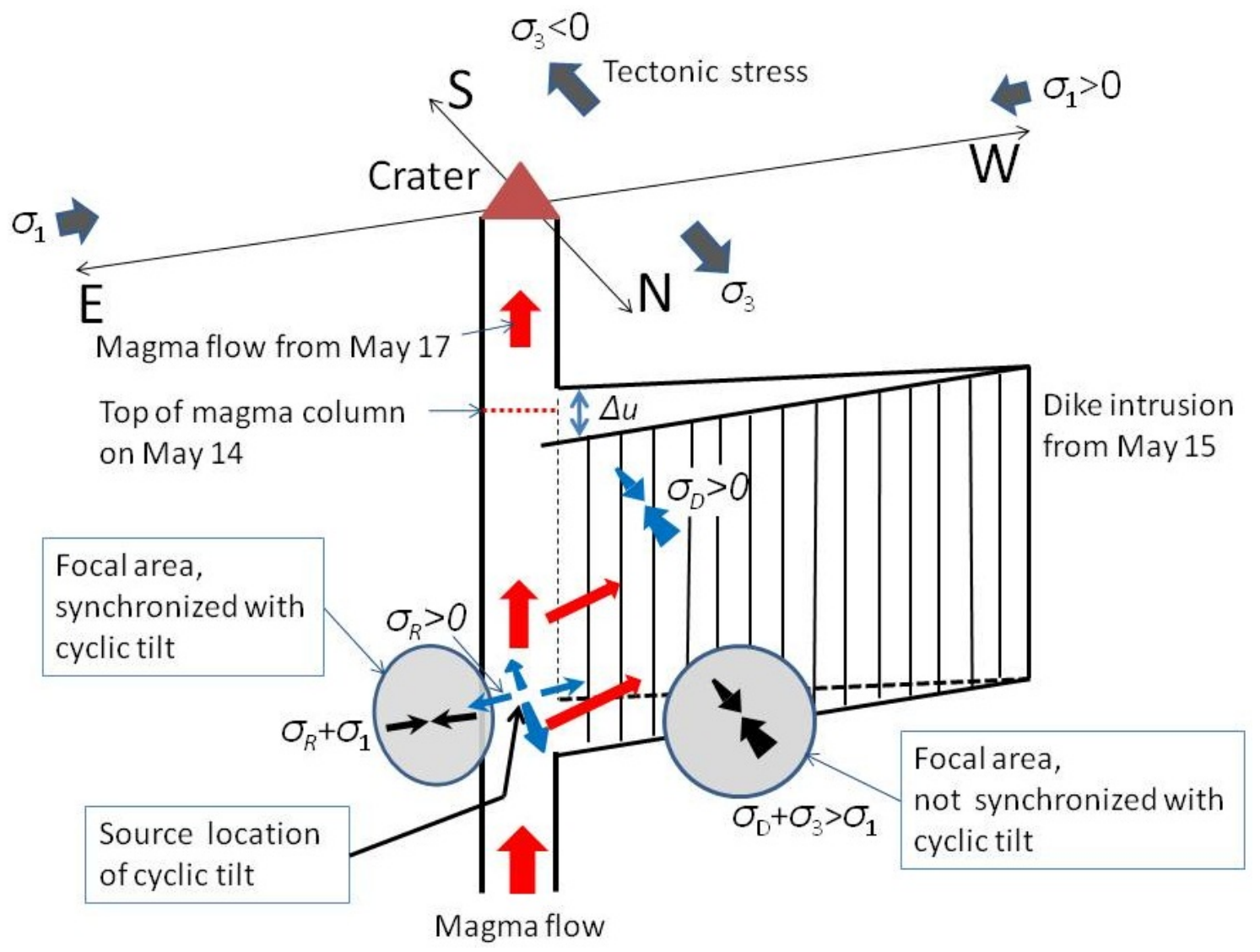

Fig. 16. Schematic illustration showing the geometric relationships among the conduit, dike, and focal areas. The model of magma ascent and dike intrusion proposed by Yamashina and Shimizu (1999) is reflected in this figure. $\sigma_{1}$ and $\sigma_{3}$ are the maximum and minimum principal stresses from the tectonic stress, respectively. $\sigma_{\mathrm{R}}$ is the local stress generated by increased pressure in the conduit, and $\sigma \mathrm{D}$ is the stress generated by the thickening of the dike $(\Delta x)$. 